\title{
The Pacing Effects on Myocardial Mechanics of the Right Ventricle Using Two-Dimensional Strain Imaging
}

\author{
A. Soliman ${ }^{*}$, W. Fareed1, A. Katta ${ }^{2}$, R. Yaseen ${ }^{1}$ \\ ${ }^{1}$ Cardiology Department, Faculty of Medicine, Menoufia University, Al Minufya, Egypt \\ ${ }^{2}$ National Heart Institute, Giza, Egypt \\ Email: ${ }^{*}$ raesoliman@hotmail.com
}

How to cite this paper: Soliman, A., Fareed, W., Katta, A. and Yaseen, R. (2020) The Pacing Effects on Myocardial Mechanics of the Right Ventricle Using Two-Dimensional Strain Imaging. World Journal of Cardiovascular Diseases, 10, 247-256.

https://doi.org/10.4236/wjcd.2020.105023

Received: April 3, 2020

Accepted: April 27, 2020

Published: April 30, 2020

Copyright $\odot 2020$ by author(s) and Scientific Research Publishing Inc. This work is licensed under the Creative Commons Attribution International License (CC BY 4.0).

http://creativecommons.org/licenses/by/4.0/

(c) (i) Open Access

\begin{abstract}
Objective: Our study aimed to assess the 6 months effect of right ventricular apical (RVA) pacing on RV longitudinal systolic strain (LSS) using two-dimensional speckle tracking echocardiography (2D STE). Background: RVA pacing differs from the natural conduction through His-Purkinje fibers in having slower conduction velocity as well as altering the normal myocardial sequences of activation. Despite the fact that numerous studies have investigated the effects of RVA pacing on the LV, data on the effects on the RV function remain scarce. 2-D STE permits an objective and quantitative assessment of segmental and global myocardial function and has been validated against tagged MRI. We used 2-D STE to evaluate the RV LSS in response to RVA pacing. Methods: This case-control study was carried out on 60 subjects (30 patients implanted with DDD devices for $3^{\text {rd }}$ degree AV block +30 age and sex matched controls) in the period between February 2018 and February 2020 in the Cardiology Department, Faculty of Medicine, Menoufia University. The patients were evaluated 6 months after their implantation using conventional echo, M Mode, Doppler and 2D STE. 2D STE was used to identify the LSS of RV myocardial segments at the time of aortic valve closure. Statistical analysis was conducted using SPSS software v 20. Results: Results revealed that RVA pacing resulted in a statistically significant reduction of the global RV LSS in patients with DDD pacemakers vs controls $(\mathrm{P}<0.05)$. Segmental analysis demonstrated reduction of LSS values of all segments of the RV free wall and interventricular septum $(\mathrm{P}<0.05)$. The greatest difference between the two groups was found in the apical segments $(\mathrm{P}<0.05)$. Conclusion: RVA pacing reduces the RV free wall and the global RV LSS. Apical segments were the most affected.
\end{abstract}

\section{Keywords}

Right Ventricle, Strain, Pacing 


\section{Introduction}

The advent of pacemakers had a significant impact on the quality of life of patients suffering from conduction problems [1]. However, RV apical pacing itself comes with the price of inflicting alterations in myocardial functions that may have deleterious clinical consequences [2] [3]. RVA pacing differs from the natural conduction through His-Purkinje fibers in having slower conduction velocity as well as altering the normal myocardial sequences of activation [4] [5]. Despite the fact that numerous studies have investigated the effects of RVA on the $\mathrm{LV}$, data on the effects on the RV function remain scarce. 2-D STE permits an objective and quantitative assessment of segmental and global myocardial function and has been validated against tagged MRI [6]. We used 2-D STE to evaluate the RV longitudinal strain (LSS) in response to RVA pacing.

\section{Subjects and Methods}

\subsection{Subjects}

This case-control study was carried out on sixty subjects in the Cardiology Department of the Faculty of Medicine, Menoufia University. Subjects in this study included thirty patients and thirty age and sex matched apparently healthy volunteers as controls (Group I). During the period between February 2018 and February 2020, the patients enrolled were identified as those implanted with dual chamber pacemakers (DDD) in our department for the management of permanent third-degree $\mathrm{A}-\mathrm{V}$ block. The patients were evaluated during their routine programming session after 6 months from their implantation. All subjects were enrolled in this study after obtaining their written informed consent and acquiring the approval of the Ethics Committee of the Menoufia University.

Inclusion criteria for the patients: 1) Patients were identified as those implanted with DDD pacemakers (6 months post implant) as a treatment of permanent $3^{\text {rd }}$ degree AV block. Third degree AV block was identified in ECG by: regular P-P interval, regular R-R interval, lack of apparent relationship between the $\mathrm{P}$ waves and the $\mathrm{QRS}$ complexes (A- $\mathrm{V}$ dissociation) and more $\mathrm{P}$ waves are present than QRS complexes. 2) The atrial lead was placed in the right atrial appendage and the ventricular lead placed in the right ventricular apex using active fixation leads (confirmed by fluoroscopy). 3) Patients should have LV EF of $>50 \%$. 4) Pacemaker telemetry should indicate atrial pacing to be less than $30 \%$ (i.e. atrial rhythm dominated by intrinsic sinus activity) and ventricular pacing should be over $90 \%$ of the time (i.e. ventricles are pacemaker dependent). Exclusion criteria of the patients included: 1) DDD pacemakers implanted for indications other than permanent third degree (complete) heart block (e.g. intermittent 3rd degree HB, Mobitz II HB, symptomatic sick sinus syndrome... etc.). 2) Ventricular lead placed outside the right ventricular apex (e.g. septal). 3) DDD pacemakers implanted less than 6 months before enrollment. 4) Patients with chronic or paroxysmal supraventricular or congenital heart block. 5) Unsatisfying echocardiographic images. 6) Presence of congenital heart disease as 
ebstein anomaly or left to right shunts ... etc. 7) Previous cardiac surgery (e.g. valve replacement, valve repair, CABG, repaired defect) or cardiac interventional procedures as PCI. 8) Structural heart disease; hypertrophic obstructive cardiomyopathy, restrictive cardiomyopathy, dilated cardiomyopathy, ischemic cardiomyopathy. 9) Presence of moderate or severe valve lesions (stenosis or regurge). 10) Pericardial disease (pericardial effusion, constrictive pericarditis). 11) Evidence of pulmonary hypertension with EPASP $>40 \mathrm{mmHg}$. 12) Resting ECG or echocardiographic evidence of myocardial ischemia. As for controls, inclusion criteria included: 1) Age and sex matched to patients. 2) Intrinsic atrial sinus rhythm followed by normally conducted ventricular activation. 3) LV EF > $50 \%$. Exclusion criteria for controls involved: 1) History of any supraventricular or ventricular dysrhythmia. 2) Having abnormally conducted ventricular activation by surface ECG (RBBB, LBBB, LAHB, LPHB, grade I A-V block). 3) LV EF $<50 \%$. 4) EPASP $>40 \mathrm{mmHg}$

\subsection{Methods}

The subjects were divided into two groups as the following; Group I: Controls with normal sinus rhythm and normal conduction and Group II: Patients with DDD pacemakers for $3^{\text {rd }}$ degree AV block. All patients underwent history taking, physical examination and routine ECG. A transthoracic echocardiographic examination was performed using vivid e9, general electric health care (GE Vingemed, Norway) equipped with a harmonic M5S variable frequency (1.7 - 4 $\mathrm{MHz}$ ) phased-array transducer while the patient was in the left lateral position based on recommendations of the American Society of Echocardiography (ASE) [7].

Routine 2-D and M Mode evaluation of the left ventricle were done to evaluate LV dimensions and ejection fraction [8]. Also, for the right side of the heart, 2D measurements were done in the apical 4 chamber view during end-diastole to evaluate the right ventricular transverse basal internal dimensions at the level of tricuspid annulus [9]. M-mode was done on the tricuspid valve annulus at the right ventricular free wall to assess TAPSE (Tricuspid annular plane systolic excursion) which was quantified as the length of the excursion of the tricuspid annular plane during systole [10]. Continuous wave doppler was done for the tricuspid valve to exclude any valvular problem and to evaluate EPASP [11].

Assessment of the RV strain by 2D STE was done by obtaining the modified apical 4 chamber view and then tracing the endocardial borders of the endsystolic frame. On the basis of this line, the computer automatically created a region of interest (ROI) including the entire transmural wall, and the software selected suitable natural acoustic markers (speckles) moving with the tissue for tracking. The software algorithm then tracked the speckle patterns on a frame by frame basis using the sum of absolute difference algorithm timed to the aortic valve closure. Finally, the software automatically tracks and accepts segments of good 
tracking quality and rejects poorly tracked segments, while allowing the observer to manually override its decisions based on visual assessments of tracking quality [12]. Image analysis was performed offline on a personal computer (PC) workstation using custom analysis software (Echopac PC, Version 113, GE Healthcare).

Longitudinal systolic strain was assessed for the RV free wall and interventricular septum. Each wall was divided into three segments; basal, mid, and apical. Value of longitudinal systolic strain (LSS) of each segment at the time of aortic valve closure was calculated and then used to estimate the average of each wall. The average of all segments combined was considered as the global RV strain.

\subsection{Statistical Methods}

Statistical presentation and analysis of the present study was conducted using the mean, standard deviation (SD) and student t-test by statistical package for social science (SPSS) V20 software for windows. Regarding the statistical testing, $\mathrm{p}<0.05$ was considered statistically significant.

\section{Results}

Regarding gender, the controls (Group I) included 16 females and 14 males while the patients (Group II) included 18 females and 12 males with no statistical difference between the two groups ( $\mathrm{P}$ value $>0.05$ ) shown in Table 1 . Regarding age, there was no statistical difference between the mean values of the controls (Group I) and the patients (Group II) (P value $>0.05$ ) as shown in Table 2.

By taking the medical history from the patients, there was no significant statistical difference between the controls (Group I) and the patients (Group II) regarding smoking, diabetes mellitus and hypertension ( $\mathrm{P}$ value $>0.05)$ as shown in Table 3.

Table 1. Comparison between the controls (Group I) and the patients (Group II) regarding gender.

\begin{tabular}{|c|c|c|c|c|c|c|c|c|}
\hline \multirow{3}{*}{ Gender } & \multicolumn{6}{|c|}{ Groups } & & \\
\hline & \multicolumn{2}{|c|}{$\begin{array}{c}\text { Group I }(\mathrm{n}=30) \\
\quad(\text { Controls })\end{array}$} & \multicolumn{2}{|c|}{$\begin{array}{c}\text { Group II }(\mathrm{n}=30) \\
\text { (Patients) }\end{array}$} & \multicolumn{2}{|c|}{ Total $(n=60)$} & \multicolumn{2}{|c|}{ Chi-Square } \\
\hline & $\mathbf{N}$ & $\%$ & $\mathrm{~N}$ & $\%$ & $\mathbf{N}$ & $\%$ & $\mathrm{X}^{2}$ & P-value \\
\hline Male & 14 & 46.6 & 12 & 40 & 26 & 43.3 & & \\
\hline Female & 16 & 53.4 & 18 & 60 & 34 & 56.7 & 2.347 & 0.988 \\
\hline
\end{tabular}

Table 2. Comparison between the controls (Group I) and the patients (Group II) regarding age.

\begin{tabular}{|c|c|c|c|c|}
\hline \multirow[b]{2}{*}{ Age } & \multicolumn{2}{|c|}{ Groups } & \multicolumn{2}{|c|}{ T-Test } \\
\hline & $\begin{array}{c}\text { Group I } \\
(\text { Controls })(n=30)\end{array}$ & $\begin{array}{c}\text { Group II } \\
\text { (Patients) }(n=30)\end{array}$ & $t$ & $P$-value \\
\hline Range & $46-68$ & $49-72$ & & \\
\hline Mean \pm SD & $59.63 \pm 6.672$ & $62.6 \pm 5.028$ & -1.945 & 0.057 \\
\hline
\end{tabular}


Table 3. Comparison between the controls (Group I) and the patients (Group II) regarding smoking, diabetes mellitus and hypertension.

\begin{tabular}{|c|c|c|c|c|c|c|c|c|}
\hline \multirow{3}{*}{ Medical History } & \multicolumn{6}{|c|}{ Groups } & & \\
\hline & \multicolumn{2}{|c|}{$\begin{array}{c}\text { Group I } \\
(\text { Controls) }(\mathrm{n}=30)\end{array}$} & \multicolumn{2}{|c|}{$\begin{array}{c}\text { Group II } \\
\text { (Patients) }(n=30)\end{array}$} & \multicolumn{2}{|c|}{ Total $(n=60)$} & \multicolumn{2}{|c|}{ Chi-Square } \\
\hline & $\mathbf{N}$ & $\%$ & $\mathbf{N}$ & $\%$ & $\mathrm{~N}$ & $\%$ & $\mathrm{X}^{2}$ & $P$-value \\
\hline Smoking & 6 & 20 & 7 & 23.33 & 13 & 21.67 & 0.098 & 0.754 \\
\hline Diabetes Mellitus & 9 & 30 & 4 & 13.33 & 13 & 21.67 & 2.455 & 0.117 \\
\hline Hypertension & 12 & 40 & 18 & 60 & 30 & 50 & 2.4 & 0.121 \\
\hline
\end{tabular}

Our results showed that despite the RV basal dimension did not have a statistical difference between the two groups (P value $>0.05)$, the lateral TAPSE had a reduced value in Group II in comparison to Group I $(\mathrm{P}<0.001)$ as shown in Table 4.

Two-dimensional STE revealed that the global RV LSS showed a statistically significant lower mean value of the patients (Group II) than the controls (Group I) (P value $<0.001$ ) as shown in Table 5 and illustrated in Figure 1.

Segmental analysis of 2-D STE the RV free wall revealed that the LSS showed a statistically significant lower mean value of all the segments of the patients (Group II) than the controls (Group I) (P value $<0.05$ ) as shown in Table 6. The apical segments showed the greatest difference in mean values as illustrated in Figure 2.

Segmental analysis of 2-D STE the interventricular septum revealed that the LSS showed a statistically significant lower mean value of all the segments of the patients (Group II) versus the controls (Group I) (P value $<0.001$ ) as shown in Table 7 and Figure 3. The apical segments showed the greatest difference in mean values.

\section{Discussion}

Evidence supports that pacemakers made a significant impact on the quality of life of patients suffering from conduction problems [13]. Unfortunately, RV apical pacing itself induces alterations in myocardial functions that may have harmful clinical sequalae [2] [3]. RVA pacing differs from His-Purkinge system in having slower conduction velocity as well as altering the natural myocardial sequences of activation [4] [5]. The effect of RVA pacing on the LV has been thoroughly investigated by several studies. Studies as MOST [14], DAVID [15] and MADIT II [16] indicated that ventricular dyssynchrony induced by pacing can create an anatomical and functional substrate capable of impairing heart function in the long term. They observed an increase in the risk of atrial fibrillation, mitral regurgitation and hospital admissions due to heart failure in patients with a high percentage of RVA paced beats, particularly those with ventricular dysfunction prior to the implant [17]. 
Table 4. Comparison between the controls (Group I) and the patients (Group II) regarding RV basal dimension and tricuspid annular plane systolic excursion (TAPSE).

\begin{tabular}{cccccc}
\hline & & \multicolumn{2}{c}{ Groups } & \multicolumn{2}{c}{ T-Test } \\
\cline { 3 - 6 } & Item & $\begin{array}{c}\text { Group I } \\
\text { (Controls) }(\mathbf{n}=\mathbf{3 0})\end{array}$ & $\begin{array}{c}\text { Group II } \\
(\text { Patients })(\mathbf{n}=30)\end{array}$ & $\mathrm{t}$ & P-value \\
\hline $\begin{array}{c}\text { RV basal } \\
(\mathrm{cm})\end{array}$ & Range & $2.7-3.9$ & $2.5-3.9$ & -1.866 & 0.067 \\
$\begin{array}{c}\text { TAPSE } \\
(\mathrm{cm})\end{array}$ & Mean \pm SD & $3.323 \pm 0.261$ & $3.470 \pm 0.343$ & & \\
\hline
\end{tabular}

Table 5. Comparison between the controls (Group I) and the patients (Group II) regarding the RV free wall and global RV longitudinal systolic strain (LSS).

\begin{tabular}{|c|c|c|c|c|c|}
\hline \multirow[b]{2}{*}{ LS } & & \multicolumn{2}{|c|}{ Groups } & \multicolumn{2}{|c|}{ T-Test } \\
\hline & & $\begin{array}{c}\text { Group I } \\
\text { (Controls) }(\mathrm{n}=30)\end{array}$ & $\begin{array}{c}\text { Group II } \\
\text { (Patients) }(\mathrm{n}=30)\end{array}$ & $\mathbf{t}$ & $P$-value \\
\hline \multirow[b]{2}{*}{$\mathrm{RV}$ free wall } & Range & $-28.67--19$ & $-26.53--5.87$ & \multirow[b]{2}{*}{-5.771} & \multirow[b]{2}{*}{$<0.001^{*}$} \\
\hline & & $-24+2.545$ & $-17.290+5.838$ & & \\
\hline \multirow[b]{2}{*}{ Global RV } & Range & $-25.5--17.17$ & $-22--7.9$ & \multirow[b]{2}{*}{-6.660} & \multirow[b]{2}{*}{$<0.001^{*}$} \\
\hline & Mean \pm SD & $-20.37 \pm 1.987$ & $-14.623 \pm 4.295$ & & \\
\hline
\end{tabular}

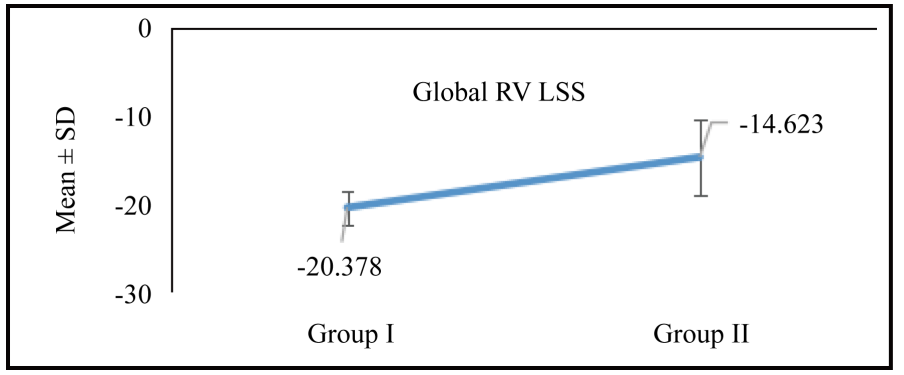

Figure 1. Comparison between the controls (Group I) and the patients (Group II) regarding the global RV longitudinal systolic strain (LSS).

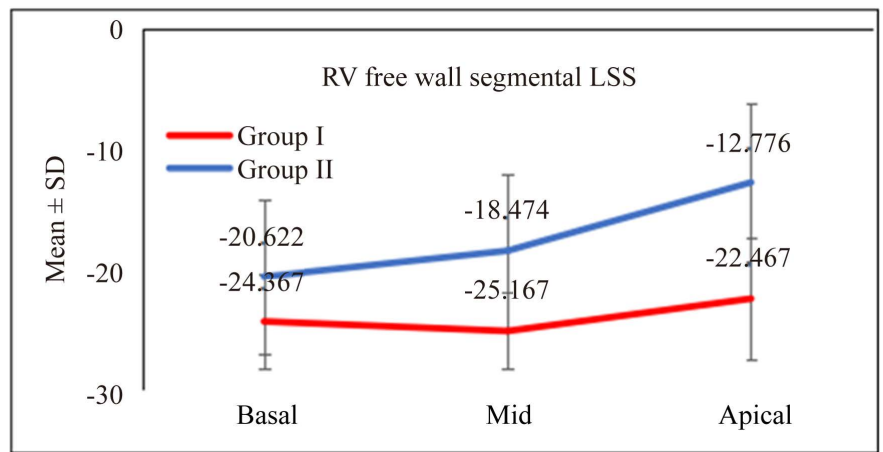

Figure 2. Comparison between the controls (Group I) and the patients (Group II) regarding longitudinal systolic strain (LSS) of segments of RV free wall. 
Table 6. Comparison between the controls (Group I) and the patients (Group II) regarding longitudinal systolic strain (LSS) of segments of RV free wall.

\begin{tabular}{cccccc}
\hline \multirow{2}{*}{ RV free wall LSS } & \multicolumn{2}{c}{ Groups } & \multicolumn{2}{c}{ T-Test } \\
\cline { 3 - 6 } & Range & Group I & Group II & t & P-value \\
\hline \multirow{2}{*}{ Basal } & Controls $)(\mathrm{n}=30)$ & (Patients) $(\mathrm{n}=30)$ & & \\
& Mean \pm SD & $-24.367 \pm 3.908$ & $-20.622 \pm 6.473$ & -2.713 & $0.009^{*}$ \\
\multirow{2}{*}{ Mid } & Range & $-31--19$ & $-29.02--4.82$ & & \\
& Mean \pm SD & $-25.167 \pm 3.163$ & $-18.474 \pm 6.422$ & -5.121 & $<0.001^{*}$ \\
\multirow{2}{*}{ Apical } & Range & $-31--16$ & $-26.39--0.06$ & & \\
& Mean \pm SD & $-22.467 \pm 5.015$ & $-12.776 \pm 6.609$ & -6.398 & $<0.001^{*}$ \\
\hline
\end{tabular}

Table 7. Comparison between the controls (Group I) and the patients (Group II) regarding longitudinal systolic strain (LSS) of segments of interventricular septum.

\begin{tabular}{cccccc}
\hline \multirow{2}{*}{ IVS LSS } & \multicolumn{2}{c}{ Groups } & \multicolumn{2}{c}{ T-Test } \\
\cline { 3 - 6 } & & $\begin{array}{c}\text { Group I } \\
(\text { Controls })(\mathbf{n}=30)\end{array}$ & $\begin{array}{c}\text { Group II } \\
(\text { Patients })(\mathbf{n}=30)\end{array}$ & $\mathbf{t}$ & P-value \\
\hline \multirow{2}{*}{ Basal } & Range & $-24--10$ & $-20--6.51$ & & \\
& Mean \pm SD & $-16.600 \pm 3.490$ & $-13.354 \pm 3.944$ & -3.376 & $\mathbf{0 . 0 0 1 *}$ \\
& Range & $-27--14$ & $-19.65--3.53$ & & \\
Mid & Mean \pm SD & $-16.967 \pm 2.953$ & $-12.348 \pm 3.809$ & -7.52 & $<0.001^{*}$ \\
& Range & $-28--14$ & $-21.29--0.03$ & & \\
Apical & Mean \pm SD & $-19.700 \pm 4.268$ & $-14.247 \pm 5.732$ & -10.31 & $<0.001^{*}$ \\
& & & & \\
\hline
\end{tabular}

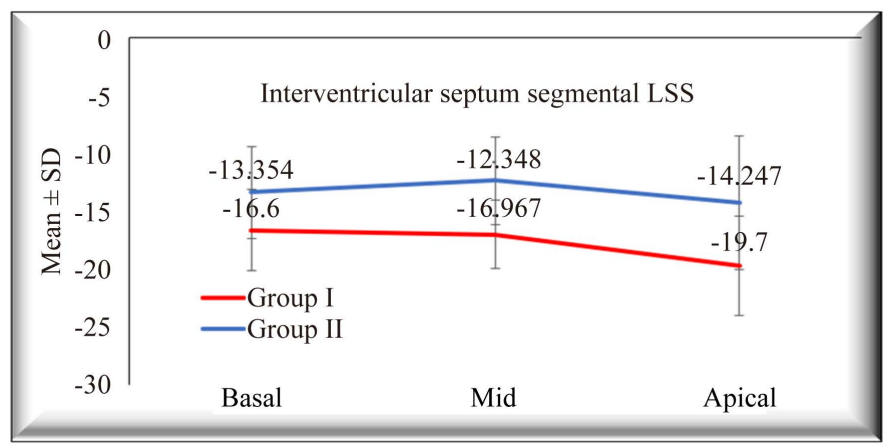

Figure 3. Comparison between the controls (Group I) and the patients (Group II) regarding longitudinal systolic strain (LSS) of segments of RV free wall.

Unfortunately, data on the effects on the RV function remain scarce. Poroyliev et al. studied the effect of 3-month RVA pacing on right and left ventricular functions of the 53 patients implanted with DDD devices. Left ventricular and RV function were assessed with TDI and speckle tracking echocardiography (STE). The patients were divided according to the percentage of cumulative ventricular pacing (Cum VP\%) into $<40 \%$ (Group 1) or $>40 \%$ (Group 2) in DDD 
mode. Their results showed that at mean follow up of 7 months there was significant decrease in GLS of LV in Group 2 ( $\mathrm{p}=0.001,95 \% \mathrm{CI}-4.28156$ to $-1.29264)$ but no change in RV global and RV free wall strain ( $\mathrm{p}=0.063 ; \mathrm{p}=$ 0.249). They concluded that permanent pacing inflicted a decrease in LV strain however the RV global and RV free wall strain were not significantly changed from their baseline parameters [18]. In a substudy of the PROTECT-PACE (Protection of left ventricular function during right ventricular pacing) study, they sought to investigate the effect of pacing on RV synchrony, RV function, and TR, and their association with LV function. Echocardiography was performed just after implantation and at 2 years. Their results showed that RV pacing appears to worsen TR, an effect which might be caused by elevated LV filling pressure due to LV dysfunction. The effect of RV pacing site on RV and TR mechanics was minor [19]. Vanturi et al. studied the effect of RVA pacing on TR grade regardless of the mechanical interference to the valve by the electrode. Their results showed that TR grade increases significantly with active RV pacing. This effect of pacing could not be attributed to acute changes in the RV area or to a possible interference with valve closure by the presence of an endovascular electrode [20].

We used 2-D STE to compare the RV LSS in patients with DDD pacemaker after 6 months (Group II) and compare them with age and sex matched controls (Group I). Our results showed that despite the RV basal dimension did not have a statistical difference between the two groups, the lateral TAPSE was mildly reduced in the patients (Group II) (P < 0.001). 2D STE of the RV revealed that global RV LSS in the patients (Group II) had a statistically significant reduced LSS mean value than (Group I) (P value $<0.001$ ). Segmental analysis of 2-D STE of the RV free wall demonstrated that the LSS had a statistically significant lower mean value of all the segments of the patient group (II) than the control group (I) (P value $<0.001)$. The apical segments showed the greatest affection. Also, segmental analysis of LSS of interventricular septum demonstrated that the there was a statistically significant lower mean value of all the segments of the patients (Group II) versus the controls (Group I) (P value < 0.001).

We explained the abovementioned results on the basis of the electromechanical alterations induced by artificial RVA pacing regarding slower conduction velocity with the resultant mechanical delay and dyssynchronous mechanical contraction. Apical segments were the greatest to be affected possibly due to inflammatory sequalae surrounding the site of lead implantation in the RV apex. RVA pacing also induced early activation of the apical segments and delayed activation of the basal segments. The combined effect of the previous mechanisms resulted in reduction of the net segmental LSS at the time of aortic valve closure reducing the effective global RV LSS.

\section{Conclusion}

RVA pacing induced electromechanical alterations in the sequence of ventricular 
activation that resulted in the reduction of the LSS of the RV free wall and Septal LSS at time of aortic valve closure. This resulted in the reduction of global RV LSS. The apical segments showed the greatest affection.

\section{Conflicts of Interest}

The authors declare no conflicts of interest regarding the publication of this paper.

\section{References}

[1] Udo, E.O., et al. (2013) Long Term Quality-of-Life in Patients with Bradycardia Pacemaker Implantation. International Journal of Cardiology, 168, 2159-2163. https://doi.org/10.1016/j.ijcard.2013.01.253

[2] Baldasseroni, S., et al. (2002) Left Bundle-Branch Block Is Associated with Increased 1-Year Sudden and Total Mortality Rate in 5517 Outpatients with Congestive Heart Failure: A Report from the Italian Network on Congestive Heart Failure. American Heart Journal, 143, 398-405. https://doi.org/10.1067/mhj.2002.121264

[3] Kashani, A. and Barold, S.S. (2005) Significance of QRS Complex Duration in Patients with Heart Failure. Journal of the American College of Cardiology, 46, 2183-2192. https://doi.org/10.1016/j.jacc.2005.01.071

[4] Prinzen, F.W., Augustijn, C.H., Arts, T., Allessie, M.A. and Reneman, R.S. (1990) Redistribution of Myocardial Fiber Strain and Blood Flow by Asynchronous Activation. American Journal of Physiology, 259, H300-H308. https://doi.org/10.1152/ajpheart.1990.259.2.H300

[5] Manolis, A.S. (2006) The Deleterious Consequences of Right Ventricular Apical Pacing: Time to Seek Alternate Site Pacing. Pacing and Clinical Electrophysiology, 29, 298-315. https://doi.org/10.1111/j.1540-8159.2006.00338.x

[6] Fine, N.M., et al. (2013) Left and Right Ventricular Strain and Strain Rate Measurement in Normal Adults Using Velocity Vector Imaging: An Assessment of Reference Values and Intersystem Agreement. The International Journal of Cardiovascular Imaging, 29, 571-580. https://doi.org/10.1007/s10554-012-0120-7

[7] Lang, R.M., et al. (2005) Recommendations for Chamber Quantification: A Report from the American Society of Echocardiography's Guidelines and Standards Committee and the Chamber Quantification Writing Group, Developed in Conjunction with the European Association of Echocardiograph. Journal of the American Society of Echocardiography, 18, 1440-1463. https://doi.org/10.1016/j.echo.2005.10.005

[8] Cameli, M., et al. (2016) Echocardiographic Assessment of Left Ventricular Systolic Function: From Ejection Fraction to Torsion. Heart Failure Reviews, 21, 77-94. https://doi.org/10.1007/s10741-015-9521-8

[9] Gripari, P., et al. (2015) Right Ventricular Dimensions and Function: Why Do We Need a More Accurate and Quantitative Imaging? Journal of Cardiovascular Echography, 25, 19. https://doi.org/10.4103/2211-4122.158420

[10] Forfia, P.R., et al. (2006) Tricuspid Annular Displacement Predicts Survival in Pulmonary Hypertension. American Journal of Respiratory and Critical Care Medicine, 174, 1034-1041. https://doi.org/10.1164/rccm.200604-547OC

[11] Testani, J.M., Sutton, M.G.S.J., Wiegers, S.E., Khera, A.V., Shannon, R.P. and Kirkpatrick, J.N. (2010) Accuracy of Noninvasively Determined Pulmonary Artery Systolic Pressure. American Journal of Cardiology, 105, 1192-1197. 
https://doi.org/10.1016/j.amjcard.2009.11.048

[12] Badano, L.P., et al. (2018) Standardization of Left Atrial, Right Ventricular, and Right Atrial Deformation Imaging Using Two-Dimensional Speckle Tracking Echocardiography: A Consensus Document of the EACVI/ASE/Industry Task Force to Standardize Deformation Imaging. European Heart Journal-Cardiovascular Imaging, 19, 591-600. https://doi.org/10.1093/ehjci/jey042

[13] Barold, S.S. (1996) Indications for Permanent Cardiac Pacing in First-Degree AV Block: Class I, II, or III? Pacing and Clinical Electrophysiology, 19, 747-751. https://doi.org/10.1111/j.1540-8159.1996.tb03355.x

[14] Lamas, G.A., et al. (2002) Ventricular Pacing or Dual-Chamber Pacing for Sinus-Node Dysfunction. The New England Journal of Medicine, 346, 1854-1862. https://doi.org/10.1056/NEJMoa013040

[15] Wilkoff, B. (2002) Dual Chamber and VVI Implantable Defibrillator Trial Investigators. Dual-Chamber Pacing or Ventricular Backup Pacing in Patients with an Implantable Defibrillator: The Dual Chamber and VVI Implantable Defibrillator (DAVID) Trial. The Journal of the American Medical Association, 288, 3115-3123. https://doi.org/10.1001/jama.288.24.3115

[16] Zhang, X., et al. (2008) New-Onset Heart Failure after Permanent Right Ventricular Apical Pacing in Patients with Acquired High-Grade Atrioventricular Block and Normal Left Ventricular Function. Journal of Cardiovascular Electrophysiology, 19, 136-141. https://doi.org/10.1111/j.1540-8167.2007.01014.x

[17] Sweeney, M.O., et al. (2003) Adverse Effect of Ventricular Pacing on Heart Failure and Atrial Fibrillation among Patients with Normal Baseline QRS Duration in a Clinical Trial of Pacemaker Therapy for Sinus Node Dysfunction. Circulation, 107, 2932-2937. https://doi.org/10.1161/01.CIR.0000072769.17295.B1

[18] Poroyliev, N., Markov, D. and Goudev, A. (2017) Effect of Right Ventricular Apical Pacing on Right and Left Ventricular Function. European Heart Journal, 38, 1716. https://doi.org/10.1093/eurheartj/ehx502.P1716

[19] Saito, M., Iannaccone, A., Kaye, G., Negishi, K., Kosmala, W. and Marwick, T.H. (2015) Effect of Right Ventricular Pacing on Right Ventricular Mechanics and Tricuspid Regurgitation in Patients with High-Grade Atrioventricular Block and Sinus Rhythm (from the Protection of Left Ventricular Function during Right Ventricular Pacing Study). American Journal of Cardiology, 116, 1875-1882.

https://doi.org/10.1016/j.amjcard.2015.09.041

[20] Vaturi, M., et al. (2010) Right Ventricular Pacing Increases Tricuspid Regurgitation Grade Regardless of the Mechanical Interference to the Valve by the Electrode. $E u$ ropean Journal of Echocardiography, 11, 550-553.

https://doi.org/10.1016/j.amjcard.2015.09.041 